\title{
ASPECTOS EPIDEMIOLÓGICOS DOS ACIDENTES FATAIS A VEICULO A MOTOR NA CIDADE DO SALVADOR (BAHIA), BRASIL
}

\author{
Celso Pugliese* \\ Fernando Carvalho * \\ Dulce Bião* \\ Celia Guimarães Neto Dias **
}

\begin{abstract}
RSPU-B/267
Pugliese, C, et al. - Aspectos epidemiológicos dos acidentes fatais a veículo a motor na cidade do Salvador (Bahia), Brasil. Rev. Saúde públ., S. Paulo, 9:271-83, 1975 .

Resumo: Foi realizado um estudo com o objetivo de descrever certos aspectos epidemiológicos dos acidentes de trânsito de veiculo a motor, na cidade do Salvador, Bahia, Brasil, o qual envolven coleta de informaçoes no Departamento de Transito (DETRAN) e no Instituto de Medicina Legal. Ficou demonstrado que os acidentes de trânsito de veiculo a motor são mais freqüentes ao fim da tarde e concentram-se, sobretudo, no fim de semana, isto é, sábado $e$ domingo. Motoristas do sexo masculino foram muito mais freqüentemente envolvidos em acidentes de transito do que os do sexo feminino. Foi concluido que os acidentes fatais envolvendo pedestres constituem-se importante problema urbano necessitando cuidadosa atenção por parte de educadores e dos serviços públicos responsáveis pelo setor do trânsito. Foi sugerida a necessidade de melhorar e tornar mais uniforme o sistema de notificação e classificação dos acidentes de veiculo a motor pelo DETRAN da cidade do Salvador.
\end{abstract} (Brasil).

Unitermos: Acidentes de trânsito. Epidemiologia. Mortalidade, Bahia

\section{INTRODUCAO}

O progresso científico e tecnológico, as transformações sócio-econômicas e o desenvolvimento da medicina, características marcantes da sociedade desenvolvida, determinaram, em curto prazo, profundas modificações no padrão de doença. Nesse período, as doenças infecciosas e parasitárias que antes ocupavam lugar de destaque como causas de mortalidade e de morbidade, foram progressivamente substituídas e. hoje. nas naçōes industrializadas verifica-se que dois terços ou um pouco mais de todos os óbitos são devido a três grupos de causas - as doenças cardiovasculares, os tumores malignos e os acidentes ${ }^{1 \tau}$.

Os acidentes no decorrer do século vinte passaram a ter considerável importância, não só como causa de óbitos e de incapacidade física permanente ou não, mas também pelas graves conseqüências econômicas que este grupo de causas determinam.

* Do Departamento de Medicina Preventiva da Faculdade de Medicina da UFBA - Parque Universitário, Canela, Salvador, BA - Brasil.

* Do Departamento de Estatística do Instituto de Matemática da UFBA - Parque Universitário, Canela, Salvador, BA - Brasil. 
PUGLIESE, C. et al. - Aspectos epidemiológicos dos acidentes fatais a veiculo a motor na cidade do Salvador (Bahia), Brasil. Rev. Saúde públ.. S. Paulo, 9:271-83, 1975.

Volkov ${ }^{1 i}$ em recente conferência fez menção que as perdas econômicas causadas por acidentes foram, para os EUA em $1969 \quad(115.000$ óbitos e 10.800 .000 acidentes), da ordem de 22.700 (milhões) de dólares. Acrescentou, também, que no mesmo período as perdas econômicas foram, para a República Federal da Alemanha ( 5 milhöes de acidentes), de vinte milhöes de marcos ou quase um quarto do orçamento da República. Em recente estudo, coordenado pela Pan-American Health Organization (PAHO) sobre os padrões de mortalidade urbana, Puffer e Griffith $^{15}$ observaram que $21 \% \quad(15,2 \%$ do sexo masculino e $5.8 \%$ do sexo feminino) de todos os óbitos, para o grupo etário de 15 a 74 anos, foram devido a causas externas. Por sua vez. Volkov ${ }^{1:}$ reportando-se a uma análise da mortalidade por acidentes, assinala que as taxas mais elevadas, por cem mil habitantes, foram registradas na França (quase 75), na República Federal Alemã (quase 64) e nos ELA (em torno de 60).

Entre os acidentes, aqueles causados por veículo a motor estão assumindo grande interesse nos dias atuais. Nos EUA, por exemplo, dos 93.800 óbitos acidentais ocorridos em 1960, $38.137(40,6 \%)$ foram devido a acidentes por veículo a motor ${ }^{16}$. Volkov ${ }^{17}$ relata, para anos recentes, taxas por cem mil habitantes, de pessoas acidentadas por veículo a motor, de 550,350 , acima de 330,300 e acima de 300 , respectivamente, para a Dinamarca, Finlândia, Islândia, Noruega e Suécia. No estudo sobre os padrões de mortalidade urbana na parte referente a acidentes de trânsito de veículo a motor, Puffer e Griffith ${ }^{15}$ encontraram taxas anuais de mortalidade por cem mil habitantes, ajustadas para a idade e por sexo bastante variáveis. Valores extremos foram observados na cidade da Guatemala $(53,0)$ e em São Paulo ${ }^{-}$(18.6) para pessoas do sexo masculino. Por seu turno, para pessoas do sexo feminino as taxas extremas de mortalidade foram observadas em São Francisco da Califórnia ${ }^{11,9}$ e em Ribeirão
Preto ${ }^{1,}$ Laurenti e col. ${ }^{s}$ analisando 33.974 acidentes de veículo a motor na cidade de São Paulo, encontraram percentuais de vítimas e de óbitos correspondentes a 62,50 e 5,13. Dados fornecidos pelo Departamento de Trânsito (DETRAN) da cidade do Salvador ${ }^{3}$ indicam que para $o$ ano de 1972 ocorreram 3.519 acidentes para 4.913 vítimas com 387 óbitos $(11.0 \%)$.

Apesar da maioria dos noticiários brasileiros 2,9 clamarem em suas edições a elevada perda diária de vidas humanas em decorrência a acidentes de trânsito, a investigação desse problema não tem despertado muito interesse no âmbito da Universidade brasileira. Mesmo assim, merecem destaque os estudos epidemiológicos conduzidos por Favero ${ }^{5}$ e por Laurenti e col. ${ }^{\&}$. 0 primeiro estudou a epidemiologia dos acidentes de trânsito em Ribeirão Preto e assinalou "que os acidentes de trânsito pelo número de pessoas lesadas e de óbitos que provocam, constituem sério problema de saúde". Laurenti e col. ${ }^{\text {, }}$ por seu turno, analisando a mortalidade por acidentes de trânsito de veículo a motor na cidade de São Paulo, em 1970, indicaram uma elevada mortalidade, mesmo fazendo-se correção para residentes.

O presente trabalho tem como objetivo analisar certos aspectos epidemiológicos dos acidentes de trânsito de veículo a motor na cidade do Salvador.

\section{MIET ODOLOGIA}

O estudo teve início em janeiro de 1972 e prolongou-se até os primeiros meses de 1973. As informações relativas aos acidentes fatais ocorridos em 1972 foram obtidas simultaneamente na Delegacia de Acidentes de Veículos (DAV) e no Instituto Médico Legal Nina Rodrigues (IMLNR).

Semanalmente era consultado o Livro de Ocorrências da DAV e todas as informações sobre acidentes fatais comunicados àquele órgão, no período, eram transfe- 
PUGLIESE, C et al. - Aspectos epidemiológicos dos acidentes fatais a veiculo a motor na cidade do Salvador (Bahia), Brasil. Rev. Saúde publ., S. Paulo, 9:271-83, 1975.

ridas para um questionário. Infelizmente, essas informaçōes não eram suficientemente detalhadas, pelo que, se passou à consulta dos processos de acidentes fatais instaurados pela DAV. Esses processos continham dados descritivos do acidente, tais como: hora, local, tipo do acidente (colisão, atropelo, etc.). a marca. o modelo e o número de veículos envolvidos no acidente. Essas informações foram consideradas referência básica para identificação do morto.

Nos arquivos do IMLNR consultava-se, semanalmente, as guias para exame do morto e transferia-se para um outro questionário determinados dados como idade, sexo, estado civil, ocupação, data do óbito e os diagnósticos de necrópsia. As características do indivíduo morto nem sempre eram descritas convenientemente e em muitas oportunidades, termos como funcionário, trabalhador, ajudante, etc., apareciam na guia definindo ocupação. Em outras oportunidades, as descrições dos dados de necrópsia eram bastante restmidas, assim sendo as especificações quanto às causas de morte e de tipos de traumatismo que levaram ao óbito, eram muito falhas.

Em dezembro de 1972, foram efetuadas as últimas visitas de rotina ao IMLNR para completar o levantamento.

Apesar desses esforços, restaram alguns casos em que não foram localizadas as rítimas de determinados acidentes, emhora existissem processos no DAV descrevendo essas ocorrências. Nessas circunstâncias, os dados referentes às vítimas foram incluídos na categoria ignorado. Finalmente, em outras oportunidades, dispúnhamos de todas as informações das vítimas. contudo no DAV não constava qualquer tipo de informação associando esta vítima a um determinado acidente de veículo. Nesse caso, julgamos ser conveniente a não inclusão do caso no estudo, assumindo-se ter sido o óbito indevidamente classificado como acidente de trânsito de veículo a motor. Todos os óbitos incluídos no estudo foram classificados segundo a Classificação Internacional de Doenças ${ }^{*}$ (1965).

Numa última tentativa se conseguiu a colaboração das autoridades do Forum Ruy Barbosa, as quais permitiram a verificação de todos os processos ali arquivados referentes ao ano de 1972. Nesse particular, o livro de tombo da Vara de Acidentes foi de grande utilidade, pois propiciou-nos aprimorar os dados sobre os acidentes fatais.

O Relatório do DETRAN ${ }^{3}$, correspondente ao ano de 1973, onde constavam informações sobre acidentes de trânsito de reículo a motor, fatais e não fatais, e que possibilitaram avaliar melhor a problemática dos acidentes fatais na cidade do Salvador.

Acidentes de trânsito de veiculo a motor 1972-1973

Em 1972 foram registradas, pelo DETRAN do município do Salvador, 3.597 ocorrências das quais 275 representaram acidentes fatais. Estes acidentes envolveram 297 motoristas e 334 veículos e causaram a morte de 302 pessoas, dando uma relação vítimas/veículos envolvidos da ordem de 1.1 para $1 . \quad O$ atropelo $(67.3 \%)$ e choque entre veículos $(14.2 \%)$ apareceram como os tipos mais comuns de acidentes fatais (Tabela 1 ).

$$
\text { TABELA } 1
$$

Distribuição dos tipos de acidentes fatais. Cidade do Salvador, 1972

\begin{tabular}{lrr}
\hline Tipos de acidentes & N.o & $\%$ \\
\hline Atropelo & 185 & 67,3 \\
Choque entre veiculos & 39 & 14,2 \\
Choque de veículo com objeto & & \\
$\quad$ nanimado & 21 & 7,6 \\
Capotamento & 16 & 5,8 \\
Queda de veiculo em movimento & 6 & 2,2 \\
Choque de veículo com bicicleta & 2 & 0,7 \\
Choque de veículo com & & 0,4 \\
$\quad$ motociclista & 1 & 1,8 \\
Ignorado & 5 & $-100,0$ \\
\hline$\quad$ Total & 275 & \\
\hline
\end{tabular}


PUGLIESE, C. et al. - Aspectos epidemiológicos dos acidentes fatais a veículo a motor na cidade do Salvador (Bahia), Brasil. Rev. Saúde públ., S. Paulo, 9:271-83, 1975.

A Figura 1 mostra-nos que sábado é o dia onde se registra maior número de acidentes $(21,8 \%)$, vindo logo em seguida o dia de domingo $(20,7 \%)$. Vale destacar, ainda, que $56,3 \%$ de todos os acidentes fatais de trânsito ocorreram entre sexta-feira e domingo.

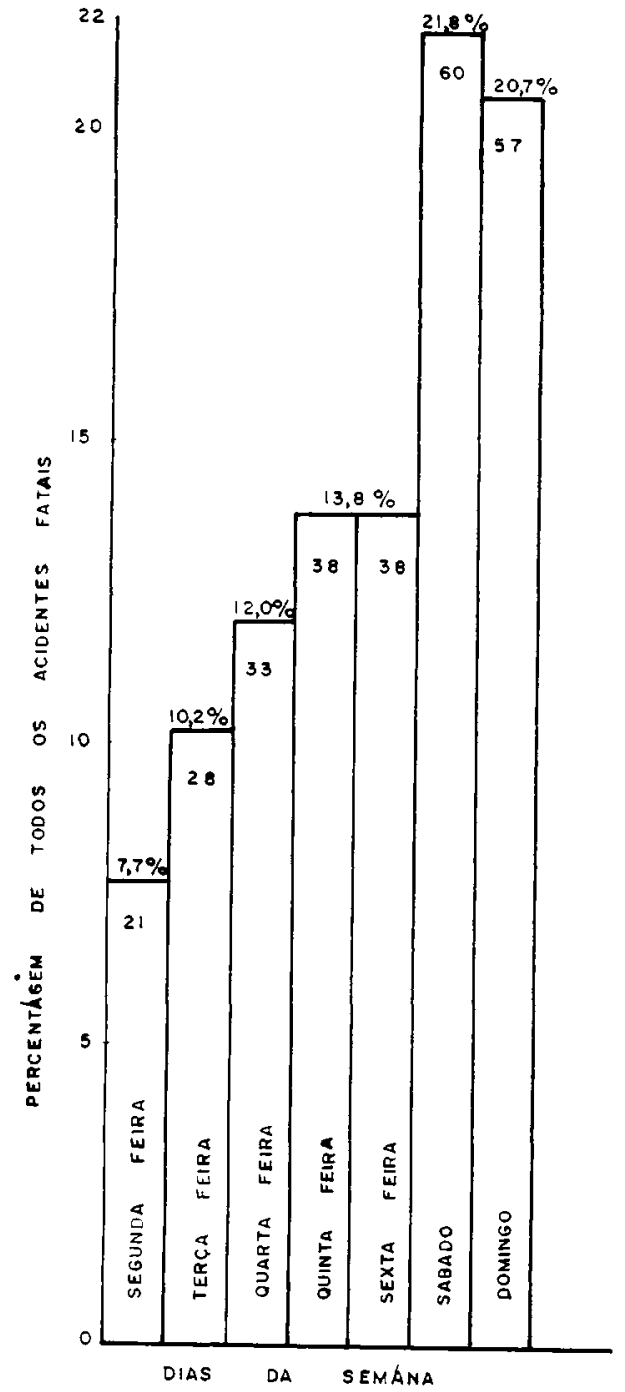

Fig. 1 - Acidentes fatais segundo os dias da semana, cidade do Salvador, 1972.

$\mathrm{Na}$ Figura 2, verifica-se que no mês de agosto se registrou o maior percentual de acidentes fatais $(12,4 \%)$, apesar de terem sido observados percentuais altos, também paar os meses de janeiro $(12,0 \%)$, março $(9,5 \%)$ e abril $(9,8 \%)$.

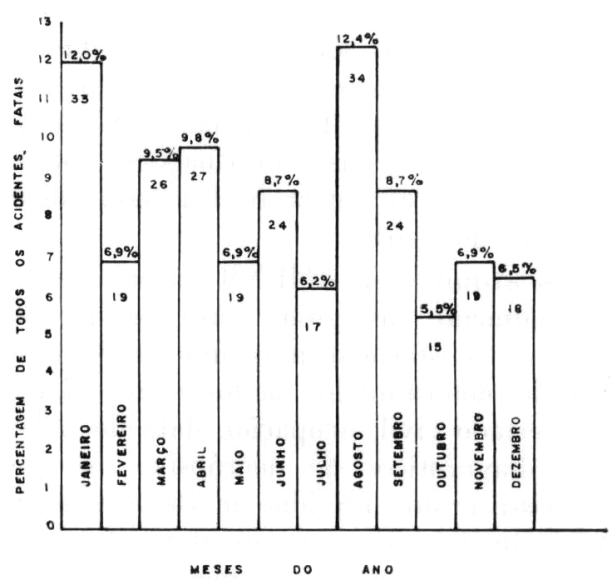

Fig. 2 - Acidentes fatais segundo os meses do ano, cidade do Salvador, 1972.

Tivemos oportunidade de analisar em relação ao tempo todos os acidentes fatais e não fatais ocorridos na cidade do Salvador em 1973. Assim sendo, quando esses acidentes foram distribuídos através das horas do dia, observou-se que nas primeiras horas da manhã o número de acidentes é mínimo. A partir das oito da manhã começa progressivamente a aumentar, para atingir um máximo entre 17 hs e 18 hs, para então novamente declinar (Figura 3). Por sua vez, a distribuição desses acidentes pelos dias da semana não difere muito da descrita para 1972 (Figura 4). Por fim, a distribuição mensal de todos os acidentes de trânsito mostra-nos maior concentração nos meses de janeiro, março e dezembro (Figura 5).

Caracteristicas dos motoristas envolvidos em acidentes de trânsito de veículo a motor 1972

A idade e o sexo dos motoristas que estiveram envolvidos diretamente nos aci- 
PUGLIESE, C. et al. - Aspectos epidemiológicos dos acidentes fatais a veiculo a motor na cidade do Salvador (Bahia), Brasil. Rev. Saúde públ., S. Paulo, 9:271-83, 1975.

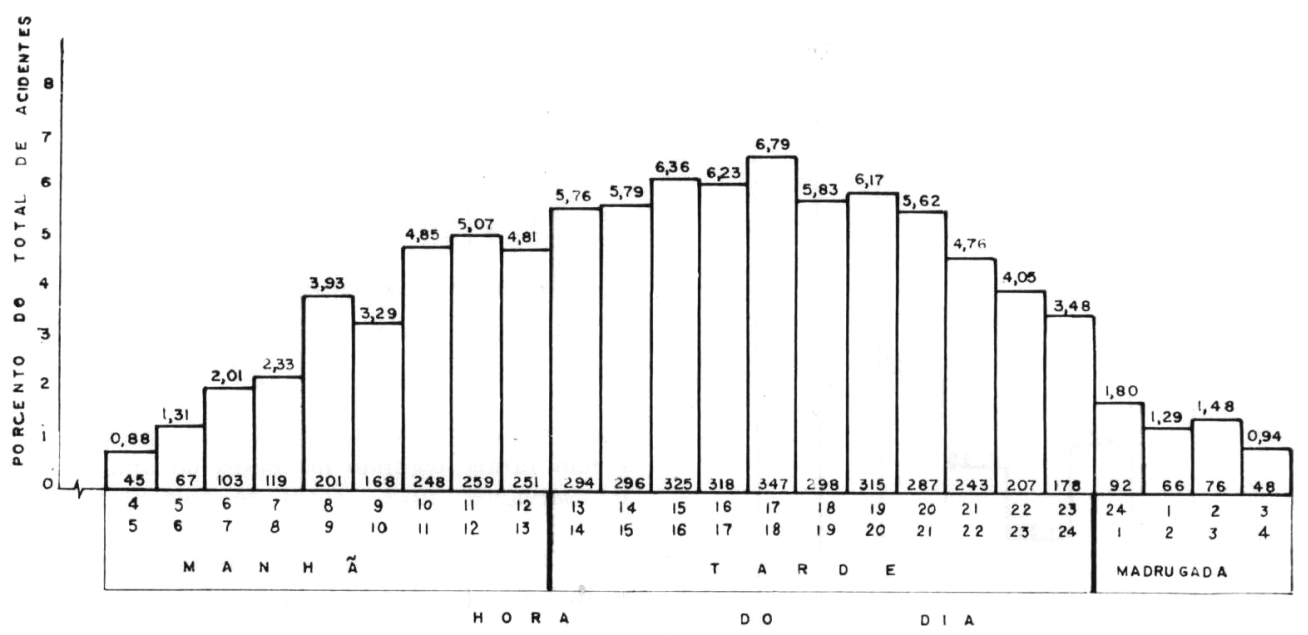

Fig. 3 - Distribuição dos acidentes fatals e não fatais segundo as horas do đia, cidade do Salvador, 1973. Total de acidentes 5.104 .

dentes aparecem na Tabela 2. Dos 297 motoristas, $19,3 \%$ tinham idade entre 15 e 24 anos; $34,7 \%$ pertenciam ao grupo etário de $25-34$ anos e $18,8 \%$ tinham idade entre 35 e 44 anos. Houve, na presente amostra, uma predominância do sexo masculino sobre o feminino com uma relação de 38,3 homens para uma mulher.

$\mathrm{Na}$ presente amostra observa-se que $50,2 \%$ dos motoristas eram profissionais, os motoristas amadores contribuiram com $21,7 \%$ e os não habilitados, isto é, pessoas não autorizadas a dirigirem no trânsito veículos a motor, contribuiram com $6,7 \%$ (Tabela 3 ).

Na Tabela 4 observa-se que o atropelo e o choque entre veículos constituíram os tipos mais comuns de acidentes de trânsito, independente do tipo de habilitação do motorista. Vale ressaltar, todavia, que os motoristas amadores $(66,7 \%$ e $23,8 \%)$ sobrepujaram aos profissionais $(61,1 \%$ e $21,4 \%)$ e aos não habilitados $(60,0 \%$ e $20,0 \%$ ).
Na Tabela 5 observa-se que quase três quartos das mortes por acidente de trânsito ocorreram entre pessoas do sexo masculino. Apesar dos acidentes fatais terem sido assinalados em todos os segmentos da população, eles foram especialmente importantes na faixa etária de 15 a 34 anos. Para este grupo etário encontrou-se $38,0 \%$ dos óbitos.

O atropelo (Tabela 6) constituiu-se, para todas as faixas etárias consideradas no presente estudo, o tipo mais comum de acidente de trânsito de veículo a motor $(63,6 \%)$. Convém destacar na mesma Tabela que os percentuais de mortes por atropelo foram mais elevados para as faixas etárias extremas, isto é, 0 a 14 anos $(91,1 \%) ; 55$ a 64 anos $(81,8 \%)$ e mais de 65 anos $(89,3 \%)$. A colisão entre veículos foi responsável por $17,3 \%$ de todas as mortes por acidentes de trânsito, sendo que os percentuais mais elevados foram registrados entre as pessoas com idade entre 20-24 anos $(21,9 \%), 25$ a 29 $\operatorname{anos}(32,2 \%)$ e $30-45$ anos $(26,9 \%)$. 
PUGLIESE, C. et al. - Aspectos epidemiológicos dos acidentes fatais a veículo a motor na cidade do Salvador (Bahia), Brasil. Rev. Saúde pribl., S. Paulo, 9:271-83, 1975.

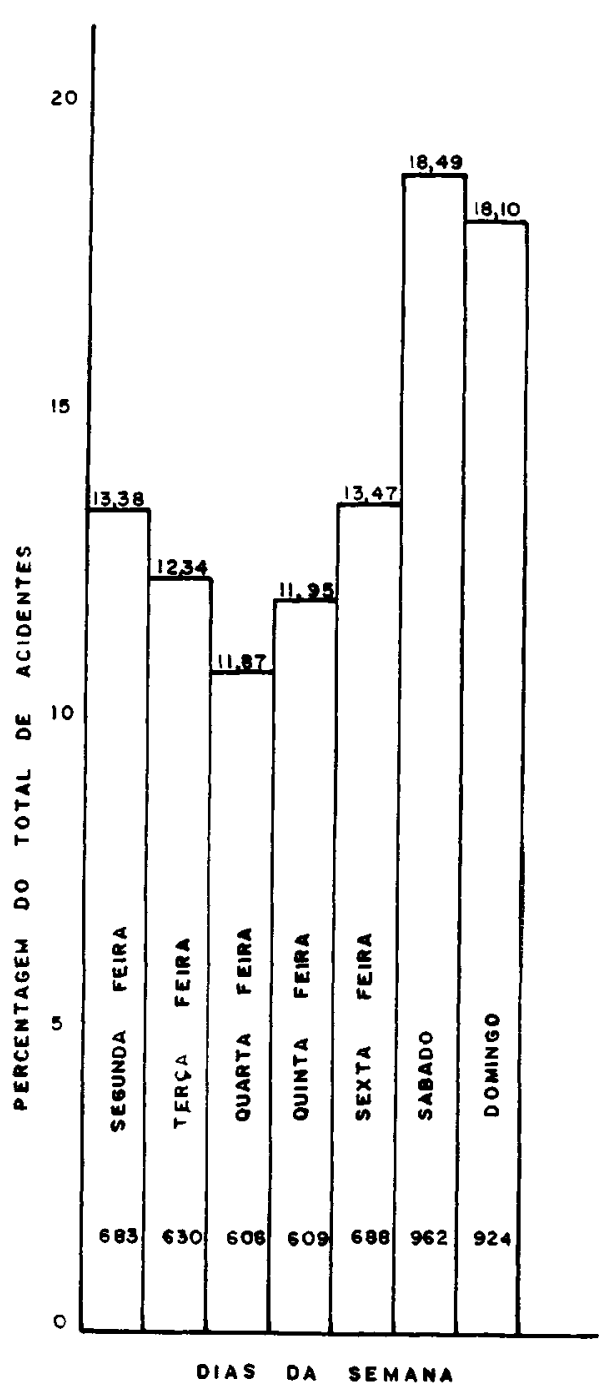

Fig. 4 - Distribuição dos acidentes fatais e não fatais segundo os dias da semana, cidade do Salvador, 1973. Total de acidentes 5.104.

Na Tabela 7 observa-se que o atropelo representou o tipo mais comum de acidente fatal por veículo a motor para as pessoas do sexo feminino. Quanto aos demais tipos de acidentes fatais, os percentuais observados foram sempre mais elevados para os indivíduos do sexo masculi-

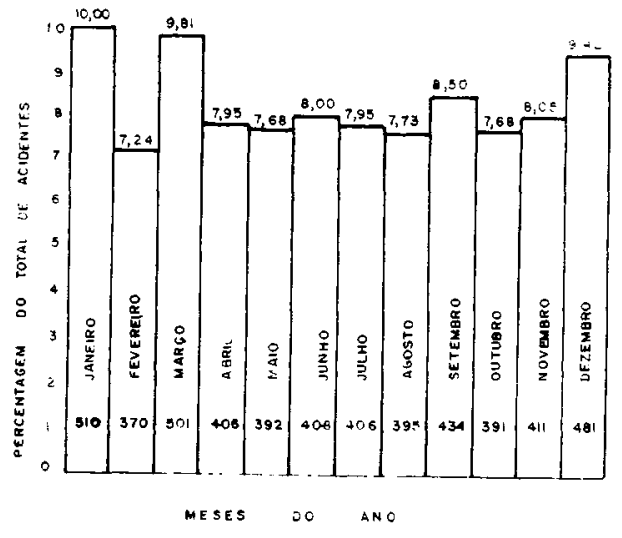

Fig. 5 - Distribuição dos acidentes fatais e não fatais segundo os meses do ano, cidade do Salvador, 1973. Total de acidentes 5.104.

no. Convém assinalar, ainda, com respeito a esta Tabela, que o capotamento, um tipo bem particular de acidente, ocorreu exclusivamente entre pessoas do sexo masculino.

$O$ intervalo de tempo decorrido entre o acidente e o óbito pode ser observado na Tabela 8. Convém esclarecer que os óbitos ocorridos no local dos acidentes e/ou durante o transporte para o hospital ou serviço de urgência foram incluídos no intervalo de um dia. Assim sendo, verifica-se que $66,9 \%$ de todos os óbitos ocorreram dentro deste intervalo, $11.9 \%$ entre 4 e 30 dias e $1,0 \%$ entre 31 e 180 dias após o acidente.

A Tabela 9 mostra que $39,7 \%$ e $33,1 \%$ dos óbitos por acidentes de trânsito foram conseqüentes a traumatismos cranianos (N850-N854) e a fraturas (N800-N829). Por sua vez, 57 óbitos $(18,9 \%)$ foram devidos a traumatismos internos do tórax, abdome e bacia (N860-N869).

Tendência da mortalidade por acidentes de trânsito de veículo a motor 1959-1972

A Tabela 10 mostra as taxas da mortalidade por cem mil habitantes dos aci- 
PUGLIESE, C. et al. - Aspectos epidemiológicos dos acidentes fatais a veiculo a motor na cidade do Salvador (Bahia), Brasil. Rev. Saúde públ., S. Paulo, 9:271-83, 1975.

TABELA 2

Motoristas envolvidos diretamente com acidentes de trânsito de veículo a motor segundo idade e sexo. Municipio do Salvador, 1972

\begin{tabular}{|c|c|c|c|c|c|c|c|c|}
\hline \multirow{2}{*}{$\begin{array}{l}\text { Idade } \\
\text { em anos }\end{array}$} & \multicolumn{2}{|c|}{ Masculino } & \multicolumn{2}{|c|}{ Feminino } & \multicolumn{2}{|c|}{ Ignorado } & \multicolumn{2}{|c|}{ Total } \\
\hline & N. ${ }^{\circ}$ & $\%$ & N.o & $\%$ & N. ${ }^{\circ}$ & $\%$ & N.0 & $\%$ \\
\hline $15-24$ & 55 & 22,0 & 2 & 33,3 & 一 & 一 & 57 & 19,3 \\
\hline $25-34$ & 101 & 40,4 & 2 & 33,3 & - & - & 103 & 34,7 \\
\hline $35-44$ & 55 & 22,0 & 1 & 16,7 & 一 & 一 & 56 & 18,8 \\
\hline $45-59$ & 19 & 7,6 & 1 & 16,7 & 一 & - & 20 & 6,7 \\
\hline Ignorado & 20 & 8,0 & $\longrightarrow$ & & 41 & 100,0 & 61 & 20,5 \\
\hline Total & 250 & 100,0 & 6 & 100,0 & 41 & 100,0 & 297 & 100,0 \\
\hline
\end{tabular}

TA B E L A 3

Motoristas envolvidos diretamente em acidentes de trânsito de veículo a motor segundo o tipo de habilitação. Municipio do Salvador, 1972

\begin{tabular}{|c|c|c|}
\hline Tipo de habilitação & N.o & $\%$ \\
\hline Profissional & 149 & 50,2 \\
\hline Amador & 63 & 21,2 \\
\hline Nāo habllitado & 20 & 6,7 \\
\hline Ignorado & 65 & 21,9 \\
\hline Total & 297 & 100,0 \\
\hline
\end{tabular}

dentes de trânsito de veículo a motor na cidade do Salvador. Observa-se que Salvador passou a experimentar, em anos recentes, um rápido aumento das taxas de mortalidade. $O$ ajustamento da reta $e$ estes dados refletem o mesmo fenômeno, isto é, os acidentes de trânsito estão em progressiva ascenção em Salvador.

\section{I S C US A O}

Adriasola e col. ${ }^{1}$ destacam a necessidade de se estabelecer um sistema unifor- me de classificação e notificação de acidente de trânsito de veículo a motor, o qual possibilite a globalização dos dados em caráter nacional. A utilização, pelos autores, de diferentes fontes de dados epidemiológicos é uma demonstração de que a notificação e a classificação dos acidentes de trânsito se faz de modo incompleto pelos agentes do DETRAN. Assim sendo, tornou-se essencial a manipulação dos processos. Essa etapa, sempre envolveu uma grande parcela de paciência e labor, pois, para que tivéssemos acesso a um determinado processo, tínhamos que esperar um mínimo de três meses e, em algumas circunstâncias, somente após o tombamento do processo era possível completar uma ficha epidemiológica de um acidente de trânsito.

Por sua vez, os laudos de autópsia eram, também, incompletos por vezes faltando informações básicas como a idade e a ocupação do indivíduo. Além disso, alguns patologistas levavam quatro a cinco meses até que apresentassem uma descrição completa da necrópsia. Este último aspecto assume maior complexidade, pois, o preenchimento do atestado de óbito nem sempre era feito com clareza, predominando, por exemplo, informações como traumatismo crânio-encefálico ou politraumatismo com fraturas expostas. Por conse- 
PUGLIESE, C. et al. - Aspectos epidemiológicos dos acidentes fatais a veículo a motor na cidade do Salvador (Bahia), Brasil. Rev. Saúde públ., S. Paulo, 9:271-83, 1975.

T A BELA 4

Tipo de acidente de trânsito de veículo a motor segundo a habilitação dos motoristas. Cidade do Salvador, 1972

\begin{tabular}{|c|c|c|c|c|c|c|c|c|c|c|}
\hline \multirow{2}{*}{$\begin{array}{l}\text { Tipo do } \\
\text { acidente }\end{array}$} & \multicolumn{2}{|c|}{ Profissional } & \multicolumn{2}{|c|}{ Amador } & \multicolumn{2}{|c|}{$\begin{array}{c}\text { Não } \\
\text { habllitado }\end{array}$} & \multicolumn{2}{|c|}{ Ignorado } & \multicolumn{2}{|c|}{ Total } \\
\hline & N.o & $\%$ & N.o & $\%$ & N.o & $\%$ & N.o & $\%$ & N.o & $\%$ \\
\hline Atropelo & 91 & 61,1 & 42 & 66,7 & 12 & 60,0 & 40 & 61,5 & 185 & 62,3 \\
\hline Choque entre veiculos & 32 & 21,4 & 15 & 23,8 & 4 & 20,0 & 7 & 10,8 & 58 & 19,5 \\
\hline $\begin{array}{l}\text { Choque de veiculos com } \\
\text { objeto inanimado }\end{array}$ & 10 & 6,7 & 3 & 4,8 & 4 & 20,0 & 5 & 7,7 & 22 & 7,4 \\
\hline Capotamento & 7 & 4,7 & 3 & 4,8 & - & - & 6 & 9,2 & 16 & 5,4 \\
\hline $\begin{array}{l}\text { Queda de veículo em } \\
\text { movimento }\end{array}$ & 7 & 4,7 & - & - & 一 & 一 & 1 & 1,5 & 8 & 2,7 \\
\hline $\begin{array}{l}\text { Choque de veículo com } \\
\text { bicicleta }\end{array}$ & 1 & 0,7 & - & - & - & - & 1 & 1,5 & 2 & 0,8 \\
\hline $\begin{array}{l}\text { Choque de veículo com } \\
\text { motocicleta }\end{array}$ & - & - & - & - & - & - & 1 & 1,5 & 1 & 0,3 \\
\hline Ignorado & 1 & 0,7 & - & - & - & - & 4 & 6,1 & 5 & 1,7 \\
\hline Total & 149 & 100,0 & 63 & 100,0 & 20 & 100,0 & 65 & 100,0 & 297 & 100,0 \\
\hline
\end{tabular}

TABELA 5

Mortes por acidente de trânsito segundo tdade e sexo. Cidade do Salvador, 1974

\begin{tabular}{|c|c|c|c|c|c|c|c|}
\hline \multirow[b]{2}{*}{ Idade } & \multirow[t]{2}{*}{ Sexo } & \multicolumn{2}{|c|}{ Masculino } & \multicolumn{2}{|c|}{ Feminino } & \multicolumn{2}{|c|}{ Total } \\
\hline & & N. ${ }^{\circ}$ & $\%$ & $\mathrm{~N} .{ }^{\circ}$ & $\%$ & N. ${ }^{\circ}$ & $\%$ \\
\hline 0 & -4 & 5 & 2,2 & 3 & 3,8 & 8 & 2,6 \\
\hline 5 & -9 & 10 & 4,5 & 8 & 10,3 & 18 & 5,9 \\
\hline 10 & -14 & 11 & 4,9 & 8 & 10,3 & 19 & 6,3 \\
\hline 15 & -19 & 15 & 6,7 & 8 & 10,3 & 23 & 7,6 \\
\hline 20 & -24 & 20 & 8,9 & 12 & 15,4 & 32 & 10,6 \\
\hline 25 & $-\quad 29$ & 26 & 11,6 & 5 & 6,4 & 31 & 10,3 \\
\hline 30 & -34 & 25 & 11,2 & 1 & 1,3 & 26 & 8,6 \\
\hline 35 & -44 & 37 & 16,5 & 8 & 10,2 & 45 & 14,9 \\
\hline 45 & -54 & 15 & 6,7 & 10 & 12,8 & 25 & 8,3 \\
\hline 55 & 一 64 & 17 & 7,6 & 5 & 6,4 & 22 & 7,3 \\
\hline \multirow{2}{*}{\multicolumn{2}{|c|}{$\begin{array}{l}65 \text { anos e mais } \\
\text { Ignorado }\end{array}$}} & 22 & 9,8 & 6 & 7,7 & 28 & 9,3 \\
\hline & & 21 & 9,4 & 4 & 5,1 & 25 & 8,3 \\
\hline \multicolumn{2}{|c|}{ Total } & 224 & 100,0 & 78 & 100,0 & 302 & 100,0 \\
\hline
\end{tabular}


PUGLIESE, C. et al. - Aspectos epidemiológicos dos acidentes fatais a veículo a motor na cidade do Salvador (Bahia), Brasil. Rev. Saúde públ., S. Paulo, 9:271-83, 1975.

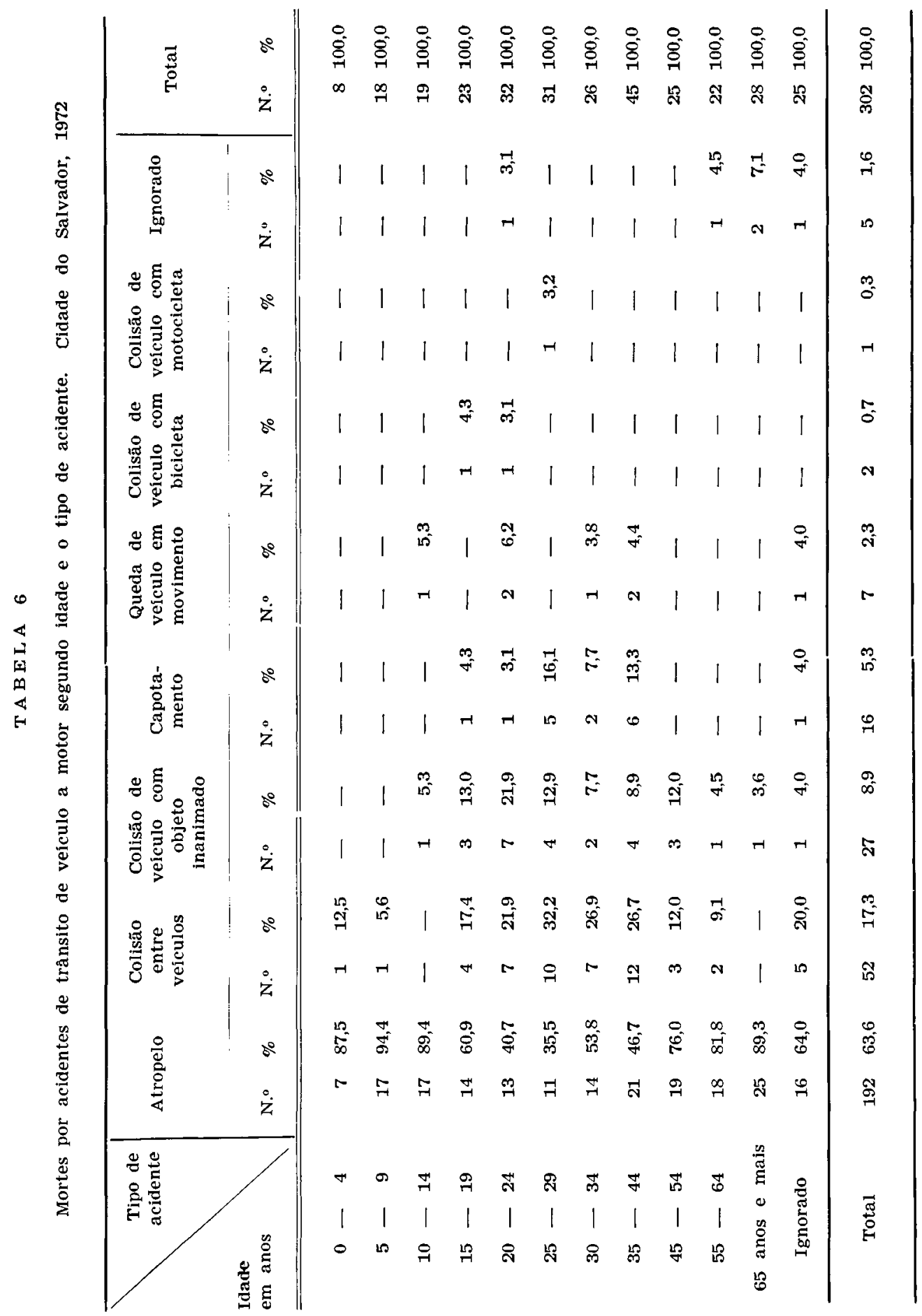


PUGLIESE, C. et al. - Aspectos epidemlológicos dos acidentes fatais a veículo a motor na cidade do Salvador (Bahla), Brasil. Rev. Saúde públ., S. Paulo, 9:271-83, 1975.

T A B E L A 7

Mortes por acidente de trânsito de veículo a motor segundo o sexo e o tipo de acidente. Cidade do Salvador, 1972

\begin{tabular}{lr|rrrrrr}
\hline & Sexo & Masculino & Feminino & & Total \\
& & N.0 & $\%$ & N.0 & $\%$ & N.0 & $\%$ \\
Tipo do acidente & & & & & & & \\
\hline \hline
\end{tabular}

TABELA 8

Intervalo decorrido em dias entre o acidente e o obito. Cidade do Salvador, 1972

\begin{tabular}{|c|c|c|}
\hline Intervalo & N. ${ }^{\circ}$ & $\%$ \\
\hline $01-1$ & 202 & 66,9 \\
\hline $11-$ & 29 & 9,6 \\
\hline $21-$ & 11 & 3,6 \\
\hline $31-$ & 20 & 6,6 \\
\hline $81-31$ & 16 & 5,3 \\
\hline $31-91$ & 2 & 0,7 \\
\hline 91 - 181 & 1 & 0.3 \\
\hline Ignorado & 21 & 7,0 \\
\hline Total & 302 & 100,0 \\
\hline
\end{tabular}

guinte. tinha-se que aguardar a descrição dos dados de autópsia para, então, completar o preenchimento da ficha correspondente do indivíduo fatalmente envolvido em um determinado acidente.

Do exposto, conclui-se que necessitamos, urgentemente, aprimorar o sistema de coleta de informaçốes sobre acidentes de trânsito e, também, educar, nos diferentes niveis de responsabilidade, os agentes responsáveis pela notificação e descrição desses eventos.
T A B E L A 9

Causas de morte por acidentes de trânsito de veículo a motor. Cidade do Salvador, 1972

\begin{tabular}{|c|c|c|c|}
\hline & Causas & N. ${ }^{\circ}$ & $\%$ \\
\hline 1. & $\begin{array}{l}\text { Externas Total ... } \\
\text { Acidentes de veiculos a mo- } \\
\text { tor (E810-E819) } \\
\text { Todos os outros acidentes } \\
\text { (E800-E827) }\end{array}$ & $\begin{array}{r}302 \\
294 \\
8\end{array}$ & $\begin{array}{r}100,0 \\
97,3 \\
2,7\end{array}$ \\
\hline 2. & $\begin{array}{l}\text { Internas Total } \\
\text { Fraturas (N800-N829) } \\
\text { Traumatismo intracraniano } \\
\text { (N850-N854) } \\
\text { Traumatismo interno do tó- } \\
\text { rax, abdome e bacia (N860- } \\
\text { N869) } \\
\text { Dilaceramento e ferimento } \\
\text { aberto da cabeça, pescoco e } \\
\text { tronco (N870-N879) } \\
\text { Dilaceramento e ferimento } \\
\text { aberto do membro inferior } \\
\text { (N890-N897) } \\
\text { Queimaduras (N940-N949) }\end{array}$ & $\begin{array}{l}302 \\
100\end{array}$ & $\begin{array}{r}100,0 \\
33,1\end{array}$ \\
\hline
\end{tabular}

Ficou evidenciado o elevado envolvimento de motoristas jovens em acidentes de trânsito (Tabela 2), concordando, pois, com o que tem sido descrito na literatura específica ${ }^{13}$. 
PUGLIESE, C. et al. - Aspectos epidemiológicos dos acidentes fatais a veículo a motor na cidade do Salvador (Bahia), Brasil. Rev. Saúde públ., S. Paulo, 9:271-83, 1975.

TAB E A 10

Taxas de mortalidade por 100.000 habitantes por acidentes de trânsito de veículo a motor. Cidade do Salvador, 1959-1972

\begin{tabular}{cccc}
\hline Ano N.0 de 6́bitos & Taxas 100.000 & hab. \\
\hline \hline 1959 & 132 & 21,0 \\
1960 & 139 & 21,3 \\
1961 & 141 & 20,9 \\
1962 & 191 & 27,3 \\
1963 & 132 & 18,3 \\
1964 & 170 & 22,8 \\
1965 & 212 & 27,6 \\
1966 & 226 & 28,5 \\
1967 & 243 & 28,4 \\
1968 & 395 & 44.3 \\
1969 & 362 & 41,9 \\
1970 & 391 & 44,1 \\
1971 & 402 & 39,1 \\
1972 & 408 & 38,8 \\
\hline
\end{tabular}

FONTE: IBGE - Séries Estatisticas Retrospectivas, 1970.

Anário Estatístico do Brasil, 1970.

Anário Estatístico do Brasil, 1973.

Indivíduos do sexo masculino apresentaram maiores percentuais de acidentes que pessoas do sexo feminino (Tabela 2). Parece ser muito difícil explicar o porque dessa diferença. McFarland ${ }^{11}$ diz que, tomando por base o número de motoristas sem considerar o quanto eles dirigem exposição ao risco de acidentes — os do sexo feminino são menos freqüentemente envolvidos em acidentes. Todavia, caso o fator exposição seja considerado e se motoristas jovens do sexo masculino dirigem três vezes mais que os motoristas da mesma idade do sexo oposto, os primeiros estarão três vezes mais expostos à possibilidade de acidentes. Nestas circunstâncias, portanto, a diferença de risco entre os dois sexos é mínima ou não existe.

Infelizmente, não nos foi possível identificar algumas variáveis específicas, de caráter temporário, relacionadas ao indivíduo e que poderiam influenciar a segurança da corrida nas rodovias, tais como: a fadiga, os efeitos do álcool, o papel de certas doenças, o uso de drogas e medicamentos. Várias estatísticas têm mostrado a influência dessas variáveis em elevar os riscos de acidentes de trânsito de veículos a motor ${ }^{7,12,14}$. Com relação a essas informações, os laudos processuais examinados mostravam-se bem incompletos. Seria, portanto, de alta conveniência que o DETRAN da cidade do Salvador procurasse estabelecer os equipamentos necessários, os quais possibilitariam uma melhor análise da influência desses fatores humanos na segurança do trânsito de veículo a motor, nas rodovias da cidade do Salvador.

O grupo ocupacional constituído por técnicos, foi o mais envolvido em acidente de trânsito, inclusive fatais. Esse grupo está, sobretudo, representado por motoristas profissionais, ou seja, motoristas de táxi. Pela própria característica, este grupo está em contínuo risco de ser envolvido em acidentes de trânsito. Assim, o motorista de táxi dirige mais durante todo o dia, compete com outros motoristas e, um fato mais agravante, o sistema contratual efetuado com os proprietários desses táxis, obriga-o a ultrapassar certos limites do bem-estar físico, para obter uma determinada féria per diem.

No estudo, observou-se que 192 pedestres $(63,6 \%)$ foram fatalmente envolvidos em acidentes de trânsito em 1972. Isso representa, ao nosso ver, um grave problema urbano. A insegurança do pedestre nas áreas urbanas decorre de vários fatores, tais como: a falta de educação do próprio pedestre, no que se refere às normas do trânsito, aos problemas de urbanização das principais vias de acesso da cidade do Salvador; a inexistência de áreas adequadas de estacionamento. Evidentemente, a solução desses problemas envolve a educação de crianças e adultos para os problemas do trânsito, como também, uma efetiva atuação dos órgãos públicos em melhorar as condições das rodovias e desenvolver medidas mais eficientes de fiscalização e controle.

Não nos foi possível derivar outros tipos de medidas comumente empregadas 
PUGLIESE, C. et al. - Aspectos epidemiológicos dos acidentes fatais a veículo a motor na cídade do Salvador (Bahia), Brasil. Rev. Saúde públ., S. Paulo, 9:271-83, 1975.

no estudo da mortalidade por acidentes de trânsito de veículo a motor ${ }^{13}$. Os dados que aparecem na Tabela 10 , por conseguinte, não podem ser usados para medir o risco relativo de um motorista de um veículo. Para tanto, teríamos que considerar, entre outros fatores, o número de quilômetros dirigidos pelo motorista, o objetivo da corrida, as condições do veículo usado e as condições da estrada, informações estas nunca registradas nas notificações nem nos laudos periciais dos acidentes de trânsito examinados.

Finalmente, gostariamos de concluir que o acidente de trânsito de veículo a motor deveria ser tratado como uma doença e, como sugere Frey ${ }^{6}$, incluído no currículo de todas escolas médicas, pois, representa, nos dias atuais um flagelo da sociedade moderna e uma causa importante de óbito.

\section{CONCLUSOES}

0 estudo ora efetuado procurou analisar descritivamente o problema dos acidentes de trânsito de veículo a motor na cidade do Salvador.
Ficou bem evidenciada a necessidade de se estabelecer um sistema uniforme de notificação e classificação criteriosa dos acidentes de trânsito ao nível do DETRAN, como, também, de tornar mais eficiente o Serviço Médico-Legal da cidade do Salvador.

A análise dos fatores humanos temporários e ligados aos acidentes de trânsito não foi possível ser realizada, pela inexistência dessas informações nas notificações e/ou nos laudos processuais examinados.

Caracterizou-se, também, o elevado percentual de óbitos entre pedestres para todos os grupos etários considerados, constituindo-se, este fato, um grave problema urbano, requerendo de um lado medidas educativas de crianças e adultos e de outro uma atuação mais efetiva dos órgãos públicos na prevenção desses acidentes.

Finalmente, indicou-se a necessidade de se considerar o acidente de trânsito de veículo a motor uma grave doença da sociedade moderna e, como tal, deveria ser incluída nos currículos de escolas médicas do país.

RSPU-B $/ 267$

Pugliese, C. et al. - [Epidemiologic aspects of fatal motor vehicle traffic accidents in the city of Salvador, Brazil]. Rev. Saúde públ., S. Paulo, 9:271-83, 1975 .

SUMmARY: A study was made aiming at the description of epidemiologic aspects of fatal motor vehicle accidents in the City of Salvador, Brazil. The study involved the collecting of data in both the Traffic Department (DETRAN) and the Legal Medicine Institute. The study showed a time relationship, i.e., the highest percentage of accidents due to motor vehicles was concentrated at noon and during weekends. Young male drivers were more frequently involved in accidents than females of the same age. The authors indicated that pedestrian fatal accidents are essencially an urban problem needing a great deal of concern by educators and providers of public services. They also suggested the necessity of improving and of homogenizing the notification and classification system of motor vehicle accidents by the DETRAN in Salvador.

UNITERMS: Accidents, traffic. Epidemiology. Mortality, Bahia, Brazil. 
PUGLIESE, C. et al. - Aspectos epidemiológicos dos acidentes fatais a veículo a motor na cidade do Salvador (Bahia), Brasil. Rev. Saúde públ., S. Paulo, 9:271-83, 1975.

\section{REFERENCIAS BIBLIOGRAFICAS}

1. ADRIASOLA, G. et al. - Prevencion de Accidentes del Transito. Bol. Ofic. sanit. panamer., 72:1-18, 1972.

2. ANALISE Revela Problemas de uma Cidade em Crise. Jornal da Bahia, 4 e 5 fev. 1973.

3. BAHIA. Secretaria de Segurança Pública (DETRAN). Relatório. Salvador, BA, 1973.

4. CLASSIFICAÇAO Internacional de Doenças: revisão, 1965. Washington, D.C., Organização Panamericana da Saúde, 1969. v. 1 (Publicação Cientifica, 190).

5. FAVERO, M. - Estudo epidemiológico dos acidentes de transito em Ribeirão Preto. Ribeirão Preto, 1971. [Tese de Doutoramento - Faculdade de Medicina de Ribeirão Preto].

6. FREY, C. F. - Motor vehicle accidents and their sequelae. $J$. med. Educ., 43:194-6, 1968.

7. HADDON Jr., W. \& BRADESS, V. A. Alcohol in single vehicle fatal accident. Experience of Westchester Country, New York. JAMA, 169: $1587-93,1959$

8. LAURENTI, R. et al. - Alguns aspectos epidemiológicos da mortalidade por acidentes de trânsito de veículo a motor na cidade de São Paulo, Brasil. Rev. Saúde públ., S. Paulo, 6:329-41, 1972.

9. LEVANTAMENTO nacional trânsito. Jor- nal do Brasil, 31 dez. 1972; 1 jan. 1973.

10. MACKAY, G. M. - Aspects of emergency care. Some features of traffic accidents. Brit. med. J., 4:799-801, 1969.

11. MCFARLAND, R. A. - The epidemiology of motor vehicle accidents. JAMA, 180:289-300, 1962.

12. McFaRLAND, R. A. \& MOORE, R. C. Human factors in highway safety: review and evaluation. New Engl. J. Med., 256 :792-8; 837-45; 890-7, 1957.

13. MARKUSH, R. E. et al. - Motor vehicle accidents in the United States (1906-1964). JAMA, 203:88-94, 1968.

14. NORMAN, L. G. - Medical aspects of roady safety. Lancet, 1039-45, 1960.

15. PUFFER, R. R. \& GRIFFITH, W. G. Patterns of urban mortality: report of the Inter-American Investigation of Mortality. Washington, D.C., PanAmerican Health Organization, 1967.

16. US Public Health Service. Accidental death and injury statistic. Washington, D.C., 1963. (Publication, 111).

17. VOLKOV, M, V. - Accidents in the social context: their prevention and treatment as a social and medical problem. The Jacques Parisot Foundation Lecture, 1973. WHO Chronicle, $27: 290-300,1973$.

Recebido para publicação em 21-03-75 Aprovado para publicacão em 04-04-75 